\title{
ETICIDADE E RECONHECIMENTO: A IMPORTÂNCIA DOS VALORES NA EDUCAÇÃO PARA OS DIREITOS HUMANOS
}

\author{
$\underline{\text { Stefanie de Almeida Macêdo }}^{\mathbf{1}}$; Carlos César Barros ${ }^{2}$
}

\author{
1Voluntária, Departamento de Ciências Humanas e Filosofia, Universidade Estadual de Feira \\ de Santana, email: stefanieamacedo@gmail.com \\ ${ }^{2}$ Orientador, Departamento de Ciências Humanas e Filosofia, Universidade Estadual de Feira \\ de Santana, email: carlosbarros@uefs.com.br
}

PALAVRAS-CHAVE: eticidade; reconhecimento; educação

\section{INTRODUÇÃO}

Fundamentada no projeto de pesquisa "Educação para os direitos humanos: eticidade e ação criativa nos diferentes contextos do brincar", a presente proposta de trabalho objetivou a compreensão dos aspectos psicológicos do conceito de eticidade (Sittlichkeit) na obra do filósofo Axel Honneth. Após dois anos de iniciação científica sobre categorias psicológicas da obra de Axel Honneth (1949-), com ênfase na constituição moral das classes oprimidas, voltamo-nos para a análise da construção dos valores na esfera comunitária, por meio do conceito de eticidade. A compreensão teórica do conceito deve subsidiar as observações a serem realizadas em escolas, nas quais observaremos a relação entre a constituição valorativa por meio do brincar em diferentes contextos, como o quilombola e o indígena.

Se tomarmos a noção de eticidade em sua concepção original, temos nos primeiros escritos de Hegel em Jena a perspectiva de uma forma de moralidade que ganha corpo nas instituições históricas - na família, na sociedade civil e no Estado (Abbagnano, 2007). Segundo Honneth (1992, p. 198), "a importância central dos primeiros escritos de Hegel para a teoria crítica social se baseia primeira e principalmente em uma teoria da eticidade na qual a "luta por reconhecimento' representa o meio abrangente do processo de formação ética do espírito". Assim, é possível compreender as lutas morais não apenas como distúrbios nas relações sociais, mas como centro da formação ética do homem. O modelo de uma luta moralmente motivada é introduzido no debate frankfurtiano por Jürgen Habermas $(1967 / 2014)$ e serve de fonte ao que vem a ser a teoria crítica de Axel Honneth $(1992 / 2003 ; 2001 / 2007 ; 2011 / 2015)$ : uma teoria do reconhecimento fundada na atualização da noção de eticidade hegeliana. Nesse modelo, a demanda mútua por reconhecimento das distintas pretensões sociais dos sujeitos instaura uma tensão normativa que pode ser definida enquanto "processo social que leva a um aumento da comunitarização, no sentido de um descentramento das formas individuais de consciência" (Honneth, 1992/2003, p. 64), portanto, uma luta por reconhecimento.

Considerando a constituição moral moderna, Axel Honneth reatualiza a noção de eticidade hegeliana, por ele considerada superinstitucionalizada. Concebendo uma ordem social concreta, se propõe a compreender a eticidade em seu momento reflexivo e a sua realização nas práticas sociais e instituições, olhando para o cotidiano intersubjetivamente. A partir deste contexto, surge a questão: como a noção honnethiana de eticidade nos auxilia a compreender os processos cotidianos de luta por reconhecimento? E como essa eticidade se vincula a uma educação para os direitos humanos? A noção de luta por reconhecimento introduzida por Axel Honneth nos permite atentar para pretensões subjetivas dos indivíduos em uma noção ampliada do direito, que não considera somente o campo jurídico, mas também o do afeto e da estima. É possível, então, compreender processos de emancipação e resistência dos sujeitos em uma educação para os direitos humanos, baseada fundamentalmente na expressão de valores. Nesse sentido, faz-se mister compreender a eticidade em situações cotidianas e concretas nos quais esses valores se manifestam e possibilitam a mudança social. 


\section{MATERIAIS E MÉTODOS}

Baseado em uma análise bibliográfica, o presente trabalho consistiu na investigação crítica do conceito de eticidade na teoria do reconhecimento de Axel Honneth. Esta investigação foi norteada por duas obras do autor nas quais o conceito é elaborado e analisado, são elas: "Luta por reconhecimento: a gramática moral dos conflitos sociais" (Honneth, 1992/2003) e "Sofrimento de indeterminação: uma reatualização da filosofia do direito de Hegel" (Honneth, 2001/2007). Por meio da análise dessas obras, percorremos o percurso realizado por Axel Honneth na tentativa de desenvolver a sua própria noção de eticidade, oferecendo subsídio para a pesquisa empírica a ser realizada em escolas posteriormente. Por se constituir basicamente enquanto uma investigação bibliográfica, este trabalho foi orientado pela metodologia científica desenvolvida por Marconi e Lakatos (2006), com as seguintes etapas de produção: identificação da bibliografia em catálogos de editoras, bibliotecas e periódicos na Internet; análise de resumos e bibliografias das obras encontradas; localização das obras relevantes para a pesquisa; compilação; fichamento; análise e interpretação das mesmas.

\section{RESULTADOS E DISCUSSÃO}

Retomando a ideia hegeliana de abordar a questão moral por um viés distinto do subjetivista, Axel Honneth nos apresenta em Luta por reconhecimento: a gramática moral dos conflitos sociais (1992/2003) uma concepção historicamente situada e atuante da autonomia como um elemento da realidade social. Neste intento, destaca a tentativa de Hegel de mediar doutrina da liberdade dos novos tempos e compreensão política antiga, moralidade e eticidade. A nova roupagem da noção de luta oferecida por Hegel apresenta nuances da filosofia da unificação de Hölderlin (1770-1843), da leitura de Platão (428-328 a.C.) e Aristóteles (348-332 a.C.) e da economia inglesa. Estes aspectos possibilitaram ao autor a crítica do caráter individualista da moral kantiana, a aproximação com a noção de intersubjetividade e a concepção de uma sociedade regida pelo mercado. O rompimento com o atomismo característico das teorias do direito natural possibilitou a Hegel a fundamentação de uma ciência filosófica da sociedade, inicialmente apresentada em seu Maneiras científicas de tratar o direito natural, de 1802. Nele, o autor conclui que tanto o direito natural empírico quanto o formal incorrem numa concepção de indivíduos isolados constituindo a sociedade, ratificando uma perspectiva atomista. Como crítica à concepção de comunidade como mera associação de pessoas, Hegel propõe a noção de "unidade ética de todos".

Tomando a pólis grega como modelo político e institucional, a filosofia política hegeliana se configura como uma tentativa de alcançar uma totalidade ética por meio de uma "comunidade eticamente integrada de cidadãos livres" (Honneth, 1992/2003, p. 40). Esta totalidade ética pode ser caracterizada como uma unidade viva, na qual se encontram liberdade universal e individual. $\mathrm{O}$ alcance deste ideal comunitário se daria por meio dos usos comunicativos e costumes exercidos em coletividade, promovendo a socialização e a individualização dos sujeitos: "a institucionalização da reciprocidade efetivada na troca é resultado da força normativa contida na palavra dada por cada um; a ação complementar é mediada por símbolos que fixam expectativas de comportamento obrigatórias" (Honneth, 1992/2003, p. 62). O caminho percorrido por Hegel em seu Sistema da Vida Ética, de 1803, se fundamenta em uma releitura da concepção de reconhecimento apresentada por Fichte: ação recíproca subjacente à relação jurídica, na qual "no apelo recíproco à ação livre e na limitação simultânea da própria esfera de ação a favor do outro, constitui-se entre os sujeitos a consciência comum, que depois alcança validade objetiva na relação jurídica" (Honneth, 1992/2003, p. 46). $\mathrm{O}$ entrelaçamento de socialização e individuação representa, portanto, a possibilidade de reconhecimento que fundamenta as relações éticas de uma comunidade, pensamento que é retomado na obra posterior de Hegel. 
Embora o pensamento hegeliano tenha ressurgido no contexto do debate filosófico, a mesma ênfase não recaiu sobre o tema da filosofia do direito, seja por questões políticas ou ontológicas. É este cenário que motiva Honneth a retomar o pensamento hegeliano dos idos de $1820 \mathrm{em} \mathrm{seu} \mathrm{Sofrimento} \mathrm{de} \mathrm{Indeterminação:} \mathrm{uma} \mathrm{tentativa} \mathrm{de} \mathrm{reatualização} \mathrm{da} \mathrm{Filosofia} \mathrm{do}$ direito de Hegel (2001/2007), no qual se propõe a pensar a filosofia a partir dos problemas do presente. É através da seara da justiça que o conceito da eticidade é mais profundamente abordado por Hegel, ainda que quase duas décadas depois da discussão introduzida pelos escritos de Jena, na Filosofia do direito. A obra de Hegel apresenta pressupostos importantes para compreensão da sociedade moderna. Entre estes, Honneth (2001/2007) destaca um quadro institucional consistente para os princípios abstratos de direito e moral, pois ratifica a crítica a uma concepção atomista de direito, bem como a defesa de padrões intersubjetivos de autorrealização individual e liberdade comunicativa na constituição dos padrões de hábitos e costumes de uma comunidade. A eticidade aparece, neste cenário, como uma "cultura de liberdade comunicativa" (Honneth, 2001/2007, p. 54). Seguindo uma crítica indireta, fundamentada em uma teoria da ação, Honneth desenvolve uma reconstituição do propósito e da estrutura básica da Filosofia do direito pela desconsideração do conceito substancialista de Estado e das instruções operativas da Lógica, remontando, portanto, ao Sistema da Vida Ética em sua relação com a teoria do reconhecimento.

Nesta reatualização, o conceito de eticidade é destacado, porque "na realidade social, encontram-se dispostas esferas de ação nas quais inclinações e normas morais, interesses e valores já se misturaram anteriormente em formas de interações institucionalizadas" (Honneth, 2001/2007, p. 52). Os costumes e hábitos se relacionam com a concepção de instituição ampliada. Assim como o direito surge como um conceito ampliado de ideia da "vontade livre universal", construído em consonância com o pensamento iluminista, no qual as determinações morais ou jurídicas devem exprimir a autodeterminação dos homens. A existência, ou Dasein, desta vontade livre, encontra-se concretamente nas condições sociais que a propiciem, ou seja, em uma ordem social justa que possibilite a liberdade comunicativa como um bem básico de todos os cidadãos. Para tanto, a sociedade deve possibilitar aos indivíduos a experiência comunicativa de ser si mesmo no outro, ou seja, o reconhecimento, por meio da participação em relações de comunicação não-desfiguradas. A impossibilidade da existência de uma vontade livre se manifesta em um sofrimento de indeterminação, caracterizado pelos sentimentos de solidão, vacuidade, abatimento. Parte deste sofrimento de indeterminação pode ser explicado por uma concepção incompleta de liberdade que é aplicada na realidade concreta, proporcionando uma compreensão falsa ou unilateral. Dois conceitos de liberdade se destacam na tradição filosófica: a reflexiva e a optativa. O conceito reflexivo de liberdade diz respeito à autonomia do sujeito frente às paixões, ratificando uma perspectiva racionalista. $\mathrm{O}$ negativo, uma ausência de limitações externas à realização da vontade; uma ação sem necessidade de prestação de contas. A estes dois conceitos, incompletos, correspondem o direito abstrato e a moral. Para Hegel, ambos recaem em uma perspectiva atomista, sendo necessária uma terceira concepção de liberdade, complexa, que venha a considerar elementos de ambos os modelos concebidos anteriormente. A superação deste sofrimento ocorreria por meio da superação das perspectivas do direito abstrato e da moralidade, que representam a coerção externa e a interna, respectivamente, alcançando a autorrealização característica da eticidade que possibilita a compreensão da justiça por meio da intersubjetividade.

Com o propósito de reconstruir gradualmente as condições comunicativas de autorrealização e liberdade, Hegel concebe as três esferas institucionais da família, da sociedade privada e do Estado como esferas de reconhecimento, correspondentes às três formas do amor, da comunidade de valores e do direito, através dos quais a eticidade se desenvolve historicamente. Para Honneth (2001/2007), no entanto, os modelos sociais característicos da modernidade apresentados por Hegel manifestam sua 'superinstitucionalização', pois se 
reduzem a esferas positivadas. Para alcançar o conceito de eticidade é necessário reunir um conceito primitivo de ação aos modelos de liberdade mais complexos para uma descrição da complexidade das realidades sociais que propiciam, ou não, a autorrealização na cotidianidade, para além das restrições impostas pelo direito formal, pois "aquele que articula todas as carências e intenções nas categorias do direito formal tornar-se-ia incapaz de participar na vida social e por isso sofreria de "indeterminação"' (Honneth, 2001/2007, p. 89). As pré-condições para a autorrealização individual são: espaço interior para compreensão de si mesmo como portador de direito; ordem moral para compreensão de uma consciência individual, como sujeitos morais. Ambas, decorrentes da ordem social justa, já que a contemplação da própria liberdade da vontade na realidade exterior necessita de acesso às coisas desejadas. Neste cenário, o sujeito é capaz de ver a si mesmo e ao outro como pessoas de direito, efetivando as pretensões jurídicas informais no direito positivo. Ou seja, conduzindo a reflexão individual ao assentimento racional da coletividade.

\section{CONSIDERAÇÕES FINAIS}

O conceito de eticidade na teoria crítica de Axel Honneth é central para compreensão da possibilidade de reconhecimento mútuo entre os indivíduos. Os costumes e valores cultivados no centro das relações partilhadas comunitariamente são o motor das constituições morais e ações dos sujeitos inseridos na luta que permite se perceber como "si-mesmo-no-outro" e, então, se autorrealizar. Para que este aspecto se efetive, Honneth (2001/2007) destaca três condições primordiais: possibilidades acessíveis de realização individual para experiência de cada sujeito como realização prática de liberdade; realização da liberdade individual na interação; determinação das ações intersubjetivas como formas determinadas de reconhecimento recíproco. Estas condições manifestam concepções morais que permanecem latentes e racionalizadas, ainda que inconscientemente, em gestos e ações não percebidas no campo dominante, mas sim na esfera do cotidiano, aproximando a eticidade dos sentimentos de injustiça, que investigamos anteriormente (Barros; Macêdo, 2015; 2016). É com tal percepção desenvolvida no trabalho cujos resultados são aqui apresentados que pretendemos ir a campo na pesquisa em curso e compreender as nuances da eticidade em cenários escolares diversos, por meio da manifestação do cotidiano e dos valores nas brincadeiras infantis.

\section{REFERÊNCIAS BIBLIOGRÁFICAS}

ABBAGNANO, N. Dicionário de filosofia. 5. ed. São Paulo: Martins Fontes, 2007.

BARROS, C.C.; MACÊDO, S.A. Moralidade e Psicologia: a consciência de injustiça social em Axel Honneth. Feira de Santana, Bahia: UEFS, 2015 (Relatório de pesquisa).

. Consciência e sentimentos de injustiça em Axel Honneth: categorias psicológicas na relação entre reconhecimento, estética e reificação. Feira de Santana, Bahia: UEFS, 2016 (Relatório de pesquisa).

HABERMAS, J. (1967). Trabalho e interação: comentários sobre a Filosofia do Espírito de Hegel em Jena. In: HABERMAS, J. Técnica e ciência como ideologia. São Paulo: Editora Unesp, 2014, pp. 35-74.

HONNETH, A. Moral development and social struggle: Hegel's early social-philosophical doctrines. In: HONNETH, A. (org.). Cultural-political interventions in the unfinished project of Enlightment. Massachusetts Institute of Technology, 1992, pp.197-217.

(1992). Luta por reconhecimento: a gramática moral dos conflitos sociais. São

Paulo: Editora 34, 2003. . (2001). Sofrimento de indeterminação: uma reatualização da filosofia do direito de Hegel. São Paulo: Esfera Pública, Editora Singular, 2007. . (2011). O direito da liberdade. São Paulo: Martins Fontes, 2015. 